\title{
On the Evaluation of Performance System Incorporating "Green Credit” Policies in China’s Financial Industry
}

\author{
Lan Xu \\ Business School, East China University of Science and Technology, Shanghai, China \\ Email: xuxx0026@ecust.edu.cn
}

Received March 29 $9^{\text {th }}, 2013$; revised May $1^{\text {st }}, 2013$; accepted May $8^{\text {th }}, 2013$

\begin{abstract}
Copyright (C) 2013 Lan Xu. This is an open access article distributed under the Creative Commons Attribution License, which permits unrestricted use, distribution, and reproduction in any medium, provided the original work is properly cited.
\end{abstract}

\begin{abstract}
The main work of this paper is aimed, through utilizing the two-stage optimization theory, to estimate the green distance functions and Malmquist green growth indexes for the China's main commercial banks and relevant financial institutions, and to further set up an overall appraisal index system to assess their performance in implementing the "Green Credit" principles. The paper also analyzes effects of the "Green Credit" policies influential on revenue achievements, as well as performs a decomposition analysis of the above impacts. The carry-outs of the paper may serve as useful references and guiding means in achieving China's economic transitional strategies of sustainable development.
\end{abstract}

Keywords: Green Credit; Sustainable Development; Financial Distance Function; Performance Evaluation

\section{Research Background}

Since reform and opening-up, China's economy develops with remarkable speed, having achieved a successful result. However, in the process of such rapid economic development, China has also paid a heavy price. An extensively developed economy has featured a blind expansion of the "highly energy consuming and highly polluted" industries, with numerous construction projects and illegal environmental phenomenon by corporations and enterprises in many areas. It becomes obvious that the environment and resources have been seriously destructed. In fact, the situation has an unfavorable impact on the social stability and sustainable economic development, and thus become the core issue of economic problems currently. The "China's 12th five-year plan" suggested that it would be an important point of strength to build a resource-conserving and environmental-friendly society as to speed up the transition of economic developing mode. It is repeatedly proved by the history of human being's progresses that, important technical innovations and economic transitions rely heavily on a wellfunctioned financial leverage accompanied by the reasonable allocation of funds and the formation of incentive mechanisms. In the processes, the operation of financial system can effecttively promote the economical innovation and transformation. In the sense, the development of "Green Finance" provides necessary prerequisites currently in realizing China's economic transition and maintaining sustainable development strategies.

The core content of "Green Finance" is the principle of "Green Credit", which refers to a series of administrative means requiring that commercial banks and other financial institutions, according to the national environmental economic policies and industrial policies, carry on researches and developments to produce pollution treatment facilities, be engaged in the ecological protection and restoration, develop and utilize new energy resources, focus on the circular economic production, green goods production, and ecological agricultural production, provide loans to support relevant enterprises and institutions and implement concessionary low interest rates, but restrict new project investments of polluting enterprises accompanied with some punishable interest rates. The principle of "Green Credit" is aimed at linking the sustainable development strategies with the financial sector, making funds and loans effecttively flow into environment-friendly enterprises and institutions, cutting off the disordered and blinded expansion of the "highly polluted and highly energy consuming" industries from the very source of the production, in order to achieve a green configuration and an allocation of social resources.

In the early 1990s, a publication of "the Financial Environment and Sustainable Development Declaration" by the Department of Environmental Program of the United Nations (UNEP) stressed that it is necessary to take into account the environmental factors in the process of the standard risk assessment, urged the banking industry to consider environmental factors in the business of management activities, and to encourage private sectors to invest production, services, and technologies beneficial to the environment. Nowadays, the environmental protection finance and "Green Credit" ideas have become an international trend, among which, one of the most influential policies are the "Equatorial Principles". That is, the financial institutions should stipulate separately the social and environmental risk assessment policies, and the implement procedures and baseline standards which are related to project financing appraisals and management activities. By the end of 2008 , over the global five continents, a total of 63 world famous institutions, including Citigroup, Netherlands Bank, HSBC, Standard Chartered Bank, and the Bank of America, all have adopted the "Equatorial Principles", their businesses cover all over the world with more than 100 countries, and the total value of those projects financed accounts for more than $85 \%$ of 
the total global market shares of financing projects (Zheng, 2008). Thus so far, typical "Green Credit" products in the global banking system mainly include: the structural energy saving collateral loans offered for instance by Citigroup and Fannie Mae, the ecological home loans offered i.e. by British Joint Financial Service, the green car loans offered i.e. by the Canadian Van City Bank and Australian MECU Bank, and the climate credit card loans offered i.e. by the European Robobank, and etc.

In the progress of implementing the "Green Credit" policies, China shows a lagged pace, but also reflects a huge potential for a future development. In July 2007, the China's Environmental Protection Administration, the People's Bank of China, and the China's Banking Regulatory Commission jointly issued the bulletin of "Opinions on the Implementation of Environmental Protection Policies and Regulations to Protect Credit Risks", putting forward to implementing the "Green Credit" policies and some specific provisions of requirements, clarifying the necessities and urgencies of implementing the policies, which marks the starting stage of China's "Green Credit" participation (CEPA, PBC, \& CBRC, 2007). According to incomeplete statistics, in recently five years, China's total amount of project loans concerning energy conservation and environmental protection has increased every year, from 202.89 billion yuan in 2006 to 964.74 billion yuan in 2010, increasing at an average rate of about $75 \%$ annually. The total numbers of project loans concerning the energy conservation and environmental protection rises from 1999 items in 2006 to 6634 items in 2010 , increasing at an average rate of $46 \%$ annually (CBA, 2010).

The adoption of "Green Credit" policies can reduce resource depletions and pollution production. Even more, it is an inevitably choice in fulfilling the sustainable economic and social development. However, there still exist many obstacles in the development process of the "Green Credit" policies, so to extensively promote the "Green Credit" rules also faces with many difficulties. The main reasons may due that there are incomplete informational symmetries in the "Green Credit" market, thus in turn leading to an unequal interest among three parties of the market executive bodies (banks, enterprises, and governments), and causing mutual game strategies between interest groups, which eventually leads to difficulty in implementing the "Green Credit" principles, and makes the whole society suffer with economic losses. In view of the context, this paper puts forward that, the top priority to implement and develop the "Green Credit" principles is to establish a set of feasible evaluation system, strengthening the standardized assessment on the effects of "Green Credit" implementation across the commercial banks and other relevant financial institutions, thus in turn to band together with laws, regulations, restraints, and incentive and punishment mechanisms, making sure that the "Green Credit" system achieve a realistic and real effective result.

\section{Research Reviews}

So far, most researches on the green credit issues are nearly based on qualitative analysis, limited to the introductory and comparative studies on the implementing status and policy regime of the "Green Credit" system across nations over the world. The goal of these researches are basically to strengthen and recognize the purposes of "Green Credit" principles, that is, to reduce environmental financial risks, call on social responsebilities for the corporations, disclose the environmental information, and enhance the effectiveness in implementing the "Green Credit" rules. Research results of this respect may include early definitions and progressive researches of environmental finances. Some scholars defined the environmental finance as a financial innovation by the financial industry demanding for the environmental production industry. For example, Marcel (Jeucken, 2001) analyzed the relationship between financial industry and sustainable development in the book of "Financial Sustainable Development and Banking Industry", emphasizing an important role that the bank may take in the environmental issues. Sonia (Labatt \& White, 2002) in her masterpiece of "Environmental Finance" discussed mainly about a relationship between the financial innovation and the environment, pointing out how financial services should carry on environmental risk assessments and provide environmental financial products. Recent studies of domestic scholars involveing in this area include journal articles by Huitong (Wang \& Chen, 2006), Huayou (Li \& Feng, 2007), and etc.

In view of difficulties in implementing the "Green Credit" policies in recent years, more researchers believe that the effects of the "Green Credit" implementation should be included in the banking and financial appraisal system, and it should formulate a set of standardized comprehensive evaluation methods at three different stages (before, in the middle of, and after) credit loans, and establish an information sharing platform for the executive bodies of governments, banks, and enterprises. Accordingly, research literatures relating to the three stages of the "Green Credit" implementation assessments can also be classified into the following three categories respecttively: 1) Environmental risk management evaluations prior to the "Green Credit" implementation; 2) Potential cost-benefit analysis on the process of implementing the "Green Credit" principles; and 3) Performance evaluations after the implementtation of the "Green Credit" principles (Chen \& Lu, 2011; Dang, 2009; Fei, 2008; Zhu \& Yu, 2011; Zhu \& Wang, 2009; Zuo \& Guo, 2010).

The purpose of this paper is to study and assess on the overall effects of implementing the "Green Credit" policies for the China's banking and financial industry through establishing a set of comprehensive assessment index system using distance functions and Malmquist productivity growth index, in addition to analyze the effects of "Green Credit" policies on the financial performances and conduct a decomposition analysis of such impacts (Grosskopf, 2003).

\section{Establishment of the “Green” Growth Index}

A traditional performance evaluation mainly focuses on comparing the operational costs of enterprises and the revenues of product sales, thus net gains come from the difference of these two items, such approach is usually called "cost-benefit analysis". For considering efficiencies and technical progresses, we can apply "Malmquist productivity growth index" to evaluate the operational performances enterprises, which is actually reflecting the abilities of resource allocation, technological transformation, and labor productivity, and the overall profitability of business sectors. Similarly, when we evaluate the comprehensive ability of making profits for the banking and financial system after implementing the "Green Credit" policies, we can also calculate the "Malmquist productivity growth in- 
dex", called the "Malmquist green credit productivity growth index", that can be used to measure the overall competitive capacities of the banking and financial industry when considering the environmental resources as one of production inputs. For the environmental resources as investment input elements cannot be measured by the price mechanism of a unified standard, we need to introduce and set up the "input-output distance function" before defining and calculating the "Malmquist green credit growth index". This is exactly the main work this paper intends to undertake.

"Green credit distance function" and thus "Malmquist green credit growth index" are of great importance in realizing the sustainable economic development and economic transition, and it provides practical means in constructing and improving the "green credit assessment system" of the financial industry.

\section{Setup of the Distance Function for the Green Credit}

In order to evaluate the operating performance for the commercial banks and other institutions, we use the "Malmquist green credit productivity growth index" to measure the overall competitive capacities of the banking and financial industry. To this purpose, we need first to construct a production technology frontier as a benchmark of the financial industry, then to compare the output level of each commercial bank and institution in the system to such benchmark reference of production frontier of the financial industry, thus in turn to obtain each institutional distance function of its own. In this sense, the "Green Credit" distance function is calculated through a set-up of the "inputoutput technology frontier" of the production operation process for the whole banking and financial system, when the environmental factors are taken into consideration as one of production inputs. In the progress of calculating the distance function for the financial institutions, we adopt the two-stage optimizational theory. First, we make use of non-parametric linear programming technique to recuperate each bank or institution's original production technology. Then, we utilize the parametric linear programming technique with a translog functional form to estimate a smooth production technological frontier for the financial industry, which is as well as best-practiced to the actual data (Xu, Bao, \& Mai, 2011).

Finally, through the above two-stage optimization linear programming approaches to obtain the estimated "Green Credit" distance function, we can further calculate the "Malmquist green credit productivity growth index" which gives explanation of the comprehensive competencies of productivity of the commercial banks and financial institutions. Afterwards, we can also perform a comparison and decomposition analysis among various financial institutions to show different status of implementation of the "Green Credit" policies.

\section{Two-Stage Estimation of Distance Function}

In the estimation of the benchmark distance function for the financial industry, we usually need to construct a reference technology frontier, so that we can compare output level of each financial institution to that reference frontier. To this purpose, we apply the first-stage of the non-parametric technology to set up such a reference frontline. In order to reflect the characteristics that there is certain dependency among production sets consecutive for several years, this research assumes a sequential technological set so that data of past history across time accumulate rather than uncorrelated within the examined time range. Specifically, for each time period, $t=1, \cdots, T$, the reference production technology models an input-output mix, $\left(x^{t-s}, y^{t-s}\right)$ with $s=0,1,2, \cdots, t=1$, using observations of previous several years as part of the technology in period $t$. This means successive production sets as to form a sequential reference frontier are nested one another (Pastor \& Lovell, 2007). In particular, the formulation of non-parametric linear programming problem for $D_{o}^{t}\left(x^{t}, y^{t}\right)$ is presented as follows:

$$
\begin{array}{ll} 
& \left(D_{o}^{t}\left(x^{k, t}, y^{k, t}\right)\right)^{-1}=\max \theta^{k} \\
\text { s.t. } & \\
\sum_{k=1}^{K} \mathrm{z}^{k, t} y_{m}^{k, t} \geq \theta^{k} y_{m}^{k, t} & m=1, \cdots, M \\
\sum_{k=1}^{K} \mathrm{z}^{k, t} x_{n}^{k, t} \leq x_{n}^{k, t} & n=1, \cdots, N \\
z^{k, t} \geq 0 & k=1, \cdots, K .
\end{array}
$$

where $z$ is an intensity variable of inputs and outputs.

In the second stage, we specify a functional form of Translog distance equation to estimate a smoothly best-practiced technological frontier for the financial sector as a whole. The advantage of parameterizing Translog functional form is that this specification is most flexible and consistent with the actual technology. More importantly, the estimated production technology enables us to deduce parameters of the input-output combination. Specifically, the functional form of the Translog distance equation in the second stage can be expressed as follows:

$$
\begin{aligned}
\ln D_{o}(x, y)= & \alpha_{0}+\sum_{m=1}^{M} \alpha_{m} \ln y_{m}+\sum_{n=1}^{N} \beta_{n} \ln x_{n} \\
& +\frac{1}{2} \sum_{m=1}^{M} \sum_{m^{\prime}=1}^{M} \alpha_{m m^{\prime}}\left(\ln y_{m}\right)\left(\ln y_{m^{\prime}}\right) \\
& +\frac{1}{2} \sum_{n=1}^{N} \sum_{n^{\prime}=1}^{N} \beta_{n n^{\prime}}\left(\ln x_{n}\right)\left(\ln x_{n^{\prime}}\right) \\
& +\sum_{n=1}^{N} \sum_{m=1}^{M} \gamma_{n m}\left(\ln x_{n}\right)\left(\ln y_{m}\right) .
\end{aligned}
$$

With the restrictions for symmetry and homogeneity imposed, we can estimate input parameters via the means of linear programming optimization as discussed previously.

\section{Calculating Malmquist “Green” Growth Index}

In order to define the "Malmquist green credit growth index", we have to specify two different time periods for the "Green Credit" distance equation, denoted as $t$ and $t+1$, then to take geometric mean value of the Malmquist index (the ratio of the distance equation) of two consecutive time periods. After manipulation, the output-based Malmquist green credit growth index can be expressed in the following form:

$$
\begin{aligned}
& M_{o}^{t+1}\left(x^{t+1}, y^{t+1}, x^{t}, y^{t}\right) \\
& =\frac{D_{o}^{t+1}\left(x^{t+1}, y^{t+1}\right)}{D_{o}^{t}\left(x^{t}, y^{t}\right)}\left[\left(\frac{D_{o}^{t}\left(x^{t+1}, y^{t+1}\right)}{D_{o}^{t+1}\left(x^{t+1}, y^{t+1}\right)}\right)\left(\frac{D_{o}^{t}\left(x^{t}, y^{t}\right)}{D_{o}^{t+1}\left(x^{t}, y^{t}\right)}\right)\right]^{\frac{1}{2}} .
\end{aligned}
$$

So, the Malmquist "Green Credit" growth index can be decomposed into two components: The efficiency changes $(\mathrm{EFFCH})$ and technological changes $(\mathrm{TECHCH})$ of the per- 
formance of financial institutions. A ratio outside the bracket is the efficiency change component, which describes relatively efficiency catch-up between two periods, $t$ and $t+1$, or sometimes called "the effect of catching-up". A geometric mean of the two ratios inside the bracket captures the shifting effect of frontiers representing the change of technology, or sometimes called "the effect of technological innovation".

\section{Empirical Researches}

The empirical analysis of this research is conducted based on the above illustration of theoretical approaches. First of all, we apply the two-stage linear programming method of optimization to estimate a benchmark production frontier reflecting the overall technological effects for the entire financial industry after implementing the "Green Credit" policy. Then we can estimate the "Green Credit" distance function for an individual financial institution, and further to specify the estimated distance functions as main components in defining and calculating the Malmquist green credit growth index that explains the overall performance of the financial industry.

In addition to utilize the often-applying input data as costs and the output data as revenues, we also need to introduce and gather the "Green Credit" data for the financial sector as part of the input costs in the production operation, through which we can estimate and calculate the "Green Credit" distance functions and the "Green Growth" index.

For processing the basic indicators of input and output data for the banks and financial institutions, we follow the methods of the intermediary approach and the capital valuation approach, existing in most financial literatures, such as Shiyu (Hou, 2006), so that various sources of deposits are regarded as part of the bank's investment inputs. In addition, human resources in the banking and financial industry account for a great amount of input costs, and the business operation expenses are also embodied by the same category as input costs. In aggregation, except for the costs incurred by the "green credit" efforts, input factors include the total amount of bank's deposits, the net value of fixed assets, and various operational expenses. On the other hand, the output data consist mainly of two parts, the interest income and the non-interest income. The first part represents the scale effect of production, the term structure of interest rates, and the industrial structure of the banking and financial system, while the latter part of non-interest income shows the profits gaining from the intermediary businesses within the financial system. The aggregation of the above two sources of revenues explains the overall abilities of profitmaking and technological innovation for the commercial banks and financial institutions.

Moreover, there are two major indicators explaining the environmental input costs of the banking and financial industry, one is the total amount of credit loans regarding to the energy conservation and environmental protection projects, which summed up to the total costs of the "Green Credit" activities. Currently to speak, the environmental project loans in China generally include credit loans of the renewable energy projects and the environmental protection projects. However, the total amount of specified "Green Credit" loans accounts for a very small portion of the total amount of credit loans for the entire financial system in China, showing that China still remains a big gap by the international experiences of some developed countries.
Another part of the "Green Financial" efforts mainly refers to the improvement of regulations on the environmental protection system and the participation of environmental executive actions of the individual financial sector. Specifically, it includes the following aspects of contents: possession of two environmental permits (license of "Green" business operation and certificate of national standard discharge) annually, annual reports on the environmental executive carry-outs, participation rates of the environmental protection activities at various administrative levels (national, provincial, and municipal), and other various supporting activities for the implementation of environmental protection rules.

Finally, by using the GAMS programming software and the SPSS statistical software that are commonly accepted in the academia, we can estimate the ten-year (2001-2010) "Green Credit" productivity growth index that reflects the overall performance of the Chinese banking and financial industry, and furthermore we can analyze the scale effect and technological effect that the "Green Credit" activities may have on the comprehensive performance of the financial system.

\section{Summary and Discussion}

This article is intended to construct a Mamlquist "Green Credit" growth index to assess a comprehensive productivity performance for the banking and financial industry of China, incorporating activities of environmental financing. Since the environmental indicators cannot be measured by market prices of uniform standards, we adopt the input-output distance function to define the Malmquist "Green Credit" productivity growth index, so that it can be avoided the disadvantage of using input prices as measures for the environmental indicators. In estimating the "Green Credit" distance functions, we first set up a benchmark technological frontier of the whole banking and financial system, and then through comparison to the reference frontier as an industrial benchmark, we can estimate the individual "Green Credit" distance functions by time and by financial institutions. Furthermore by definition, we can also calculate an integrated "Green Credit" productivity growth index for the financial sector as a whole across various time periods. Based on the above approaches, we can further discuss the effects of efficiency change and technological progress that may have impacts on the overall productivity growth in the financial industry while incorporating the environmental performance.

In addition, the paper carries on an in-depth study and discussion on the establishment and application of the appraisal system of the "Green Credit" productivity growth index both theoretically and empirically. When estimating the "Green Credit" distance functions, we apply a two-stage linear programming optimization principle to smoothen out the estimated benchmark distance functions of the entire banking and financial system, characterized with the most consistent to the actual data, but free of excessive discontinuity, periodic, and error deviation. Besides, the parameter values of the input-output combination generated from the second stage are potentially valuable, which provides the theoretical basis and practical means of computing the environmental financial expenses. Lastly, in estimating the "Green Credit" distance function and thus the Malmquist "Green Credit" productivity growth index, we apply the sequential linear programming method to stack up the historical data in constructing a continuous production 
technological frontier spanning over time, which corrects for a shortcoming by the contemporaneous approach that past experiences of production and operation over several years may be uncorrelated with each other.

\section{REFERENCES}

Chen, W. G., \& Lu, L. G. (2011). External obstacles of Green Credit of China Commercial Bank and constructing the framework of environmental risk management. Guangdong Academy Journal of Finance, 26, 66-76.

China's Banking Association (CBA) (2010). China's banking social responsibility report on 2006-2010. Beijing.

China's Environmental Protection Administration (CEPA), People's Bank of China (PBC), \& China's Banking Regulatory Commission (CBRC) (2007). Opinions on the implementation of environmental protection policies and regulations to protect credit risks. Bulletin of the China's Environmental Protection Administration, Beijing.

Dang, C. F. (2009). Thinking about our national commercial bank to promote Green Credit. Economics and Finance, 2, 51-53.

Fei, Y. (2008). On the Green Credit and environmental risk management. Operational Managers, 9, 10-14.

Grosskopf, S. (2003). Some remarks on productivity and its decompositions. Journal of Productivity Analysis, 20, 459-474. doi:10.1023/A:1027364119672

Hou, S. Y. (2006). The measurement of the dynamic productivity index of China's commercial bank. Journal of Henan Cadre Institute of Financial Management, 4, 65-69.
Jeucken, M. (2001). Sustainable finance and banking: The financial sector and the future of the planet. London: Earthscan Publications Ltd.

Labatt, S., \& White, R. R. (2002). Environmental finance: A guide to environmental risk assessment and financial products. New York: John Wiley and Sons Ltd.

Li, H. Y., \& Feng, D. F. (2007). Barriers of the implementation of environmental protection financial policy and improvement methods. Environmental Protection, 12, 38-42.

Pastor, J. T., \& Knox Lovell, C. A., (2007). Circularity of the malmquist productivity index. Economic Theory, 33, 591-599. doi:10.1007/s00199-006-0169-4

Wang, H. T., \& Chen, B. Q. (2006). Environmental finance: Financial innovation and circular economic win-win path. Shanghai Finance, 6, 29-31.

Xu, L., Bao, S. M., \& Mai, Y. (2011). Comparative researches of financial productivity on the 16 cities in China's Yangtze River Delta Region. Journal of Convergence Information Technology, 6, 235247.

Zheng, C. (2008). Green Credit: International practice and reference. Journal of Financial Management and Research, 10.

Zhu, L., \& Yu, W. Y. (2011). Interest analysis of participating the Green Credit from the perspective based on the game theory. Journal of Southern Agriculture, 42, 1025-1028.

Zhu, X. G., \& Wang, X. J. (2009). Deepening the green financial policy. World Environment, 4. 88-91.

Zuo, R. J., \& Guo, K. J. (2010). SWOT analysis on developing Green Credit in our country's commercial bank. Financial Development Research, 7, 69-72. 